\title{
EFFECTS OF SOLUTION pH ON THE FILTRATION PROFILE AND CAKE FORMATION OF AEROSOL-MODIFIED PES MEMBRANE
}

\author{
Nasrul Arahman ${ }^{1,2,3,4,}$, Fachrul Razi', Sri Mulyati', Mukramah Yusuf', \\ Syawaliah Muchtar ${ }^{1}$, Sri Aprilia ${ }^{1}$, Umi Fathanah ${ }^{1}$, Afrilia Fahrina ${ }^{1}$, \\ Diki Sukma Windana ${ }^{1}$, Sufriandy Satria ${ }^{1}$, Muhammad Roil Bilad ${ }^{5}$ \\ and M. Ahmed Ali Baig ${ }^{6}$ \\ ${ }^{1}$ Department of Chemical Engineering, Syiah Kuala University, 23111, Banda Aceh, Indonesia \\ ${ }^{2}$ Research Center for Environmental and Natural Resources, Universitas Syiah Kuala, Jl. \\ Hamzah Fansuri, No. 4, Darussalam, Banda Aceh 23111, Indonesia \\ ${ }^{3}$ Atsiri Research Center, Universitas Syiah Kuala, Jl. Syeh A. Rauf, Darussalam, Banda Aceh \\ 23111, Indonesia \\ ${ }^{4}$ Magister Program of Environmental Management, Universitas Syiah Kuala, Banda Aceh, \\ Indonesia \\ ${ }^{5}$ Department of Chemical Engineering, Universiti Teknologi PETRONAS, 32610, Bandar Seri \\ Iskandar, Perak, Malaysia \\ ${ }^{6}$ Department of Mechanical, CMR Technical Campus Kandlakoya, Medchal Road, Hyderabad- \\ 501401, India \\ ${ }^{\square}$ Corresponding Author: nasrular@unsyiah.ac.id
}

\begin{abstract}
The type and properties of the filtration solution affect the formation and thickness of the cake layer on the membrane surface. This study aims to identify the effect of the acidity of Sodium Alginate (SA) solution on the filtration profile and cake layer formation on the Polyethersulfone/Aerosol OT (PES/A-OT) membrane surface. The filtration process was carried out using a single hollow fiber module by the pressure-driven outside system with the feed flowing from the membrane's outer wall and clean water collected on the inside of the hollow fiber membrane. The $\mathrm{pH}$ solution was tested at neutral, acid, and bases, and the filtration performance of the membrane was evaluated based on water flux recovery ratio (FRR) and cake formation on the membrane surface. The results showed that SA solution with neutral $\mathrm{pH}$ produced the best FRR (up to $87.3 \%$ ) and the thinnest cake layer formation.
\end{abstract}

Keywords: Membrane, Polyether Sulfone, Fouling, Relative Permeability, Sodium Alginate

RASĀYAN J. Chem., Vol. 14, No.3, 2021

\section{INTRODUCTION}

The application of membrane technology in separation industries such as protein purification, gas separation, clean water purification, or wastewater treatment requires serious consideration regarding the properties and characteristics of the membrane. ${ }^{1-4}$ The selected membrane has to hold specific properties corresponding to those of the target solution to be separated. Such specification is designed that the filtration may operate optimally in a long run and yield a high product purity. Therefore, membranes are often produced after the type and properties of the target filtration solution have been properly identified. A filtration process will run properly with a longer life can be achieved if the membrane pores are not covered by the particles of the solution concentration on the surface, or by a phenomenon called fouling. Fouling is formed on the membrane surface due to the polarization of the particles from either organic or inorganic compounds that covers the membrane pores, thus inhibiting the filtration process. ${ }^{5}$ The formation of fouling on the membrane surface can be influenced by the properties of membrane material and the conditions of the feed solution. ${ }^{6,7}$ 
RASĀYAN J. Chem.

Vol. 14 | No. 3 |1482-1488| July - September | 2021

This study focuses specifically on the filtration process, leaving out the discussion on the selection of raw materials, methods of membrane making, or methods of modification. Various studies have been and are being carried out to identify the very factors that cause the cake layer formation on the surface and trigger fouling during the filtration process. Some researchers focused on the operating conditions of the filtration process including the type and flow rate of the feed, the operating pressure applied, and the concentration and chemical/physical properties of the feed. The Boutin Research Group studied the effect of the flow type of the ultrafiltration module on the treatment of wastewater from the rockwood industry using a commercial membrane made of polymer polyethersulfone. From a series of laboratory studies followed by mathematical model simulations, it was concluded that the filtration with a crossflow type module was better than that with a dead-end type. ${ }^{8}$ Crossflow filtration was more profitable as it could treat wastewater with high suspension concentrations and still promised a longer filtration process. Iritani focused on studying the ultrafiltration module of a dead-end type to determine the flux profile of various concentrations of bovine serum albumin (BSA) solution during the filtration period by observing the changes in real operating pressure under conditions of temporal constant operating pressure. It was found that the filtration performance depended on the concentration of BSA solution that would affect the fast or slow formation of the cake layer on the membrane surface, which, in turn, would have an impact on the changes in the filtration rate or real operating pressure during the filtration process. ${ }^{9}$

In our previous research, an in-depth study was carried out involving laboratory studies and predictions using several mathematical models to the filtration profile of liquid waste samples (sodium alginate solution) by considering the presence of other ions in the sample, namely, $\mathrm{Ca}$ and $\mathrm{Mg}$ metal ions. The results showed that the cake layer was easily formed on the membrane surface through which SA solution containing $\mathrm{Ca}$ ions passed. In other words, the filtration process of SA solution containing $\mathrm{Mg}$ ions could run longer and with a higher permeate volume compared to the samples containing $\mathrm{Ca}$ ions. ${ }^{6} \mathrm{In}$ the present work, the authors developed a study to identify the effect of the SA solution acidity on the cake layer formation on the membrane surface and the ultrafiltration profile of the PES membrane blending with AOT surfactant. This study was conducted to determine the exact thickness of the cake layer formed on the membrane surface after the filtration of SA solution in basic, neutral, and acidic $\mathrm{pH}$ conditions through laboratory experiments and mathematical models.

\section{EXPERIMENTAL}

\section{Materials}

PES (Ultrason E6020 P) with Mw 65,000 was purchased from BASF Co. Dimethylformamide (DMF), Sodium alginate (SA) was purchased from WAKO (Pure Chemical Industries, Ltd., Japan). Surfactant sodium bis(2-ethyl-hexyl) sulfosuccinate (Aerosol OT) as a membrane additive was supplied by Fluka. Sodium hydroxide and sulfuric acids to set the base and acidic solutions were obtained from Sigma Aldrich (Steinheim, Germany).

\section{Membrane Preparation}

The membrane was prepared by dissolving $18 \mathrm{wt}$ PES and AOT 5wt\% into DMF until a homogeneous polymer solution was obtained. The membrane was then printed using the dry-wet spinning method by following the procedures outlined in our previous studies. ${ }^{10}$

The obtained membrane was finally analyzed to identify several parameters of its main properties including its outer and inner diameters, hydrophilicity properties, and pure water flux. These data are as shown in Table-1.

Table-1: Membrane Specifications

\begin{tabular}{c|c|c|c|c}
\hline \multirow{2}{*}{$\begin{array}{c}\text { Membrane Length } \\
(\mathrm{mm})\end{array}$} & \multicolumn{2}{|c|}{ Membrane Diameter } & \multirow{2}{*}{$\begin{array}{c}\text { Water Contact } \\
\text { Angle }\end{array}$} & \multirow{2}{*}{$\begin{array}{c}\text { Flux } \\
\left(\mathrm{L} / \mathrm{m}^{2} . \mathrm{hr}\right)\end{array}$} \\
\cline { 2 - 3 } & Outer $(\mathrm{mm})$ & Inner $(\mathrm{mm})$ & 52.70 & 270 \\
\hline 140.00 & 3.00 & 1.00 & 50 \\
\hline
\end{tabular}

\section{Membrane Morphology}

The morphological structure of the membrane can be examined using scanning electron microscopy (SEM). The membrane sample was put in a vacuum, in which the entire sample was irradiated with electron beams 
RASĀYAN J. Chem.

Vol. 14 | No. 3 |1482-1488| July - September | 2021

with the help of an anode. At this stage, the sample would reflect new electrons which were captured by the detector, so that the reflection could be displayed on the monitor.

\section{Pressure-Driven Outside Cross Flow Module}

The entire filtration test of sodium alginate solution was designed using a single piece of hollow fiber membrane module by a pressure-driven outside cross-flow system. The procedure for the filtration process has been described in the previous research series. ${ }^{6} 50 \mathrm{ppm}$ sodium alginate solution was flowed perpendicular to the membrane outer wall using a peristaltic pump with a flow rate of 0.6 liters per minute and operating pressure of $1 \mathrm{~atm}$. Water passing through the membrane wall would flow in the lumen along the inner wall of the hollow fiber membrane and eventually collect in the permeate tank. The sodium alginate solution that could not pass through the membrane pores would flow in the shell module and collect in the retentate tank. The volume of the sodium alginate solution accumulated in the permeate tank was recorded every 10 minutes of filtration time.

\section{Filtration Model of the Foulant Solution}

The $50 \mathrm{ppm}$ sodium alginate solution was passed on the hollow-fiber membrane from the outer wall inwards with 1 bar pressure using a peristaltic pump. SA sample filtration was carried out for one hour, and the resulting permeate was weighed every 10 minutes to determine the membrane flux. The sodium alginate solution flux was calculated using Eqn.-1. Three variations of the SA sample solution acidity were set: $\mathrm{pH}$ 4 (acid), $\mathrm{pH} 7$ (neutral), and pH 14 (bases).

$$
\begin{array}{rll}
J_{p}=\frac{V}{A x \Delta t} & \\
\text { Where, } \quad \mathrm{J}_{\mathrm{p}} & =\text { flux }\left(\mathrm{L} / \mathrm{m}^{2} . \mathrm{Hr}\right) \\
\mathrm{V} & =\text { flow rate }(\mathrm{L}) \\
\mathrm{A} & =\text { area of the membrane }\left(\mathrm{m}^{2}\right) \\
\Delta t & =\text { time (hour) }
\end{array}
$$

To make it easier to understand the tendency of the flux decline in the filtration of sodium alginate solution, the normalized flux (nF) was calculated using Eqn.-2.

$$
n F=\frac{J_{p_{n}}}{J_{p_{0}}}
$$

Where,

$J_{p_{0}} \quad=$ Flux of sodium alginate solution at initial filtration $\left(\mathrm{L} / \mathrm{m}^{2} . \mathrm{Hr}\right)$

$J_{p_{n}} \quad=$ Flux of sodium alginate solution at $n$ filtration time $\left(\mathrm{L} / \mathrm{m}^{2} . \mathrm{Hr}\right)$

In another research series, membranes that had been used for sodium alginate filtration for 60 minutes were then backwashed using deionized water for five minutes. The sample filtration was then repeated twice. The filtration profile at this stage was analyzed by calculating the flux declined due to the cake layer formation on the surface of the membrane outer wall and the flux recovery ratio (PRR) due to washing. Flux decline and recovery were calculated using Eqn.-3 and 4.

$$
\begin{aligned}
& \text { Flux declined }=\left(\frac{J_{P_{0}}-J_{p_{n}}}{J_{p_{0}}}\right) \times 100 \\
& \text { PRR }=\left(\frac{J_{P_{b}}}{J_{p_{0}}}\right) \times 100
\end{aligned}
$$

Where, $\mathrm{J}_{\mathrm{Pb}}$ is the permeability of sodium alginate solution at the first 10-minute filtration after membrane backwashing.

\section{Cake Formation Vs Filtration Time}

The increase in cake thickness due to fouling $(\delta)$ on the surface of the hollow fiber cylindrical membrane was determined by calculating the difference in cake radius $\left(r_{c}\right)$ and outer membrane radius $\left(r_{0}\right)$ based on Eqn.-5.

$$
\delta=r_{c}-r_{0}
$$


RASĀYAN J. Chem.

Vol. 14 | No. 3 |1482-1488| July - September | 2021

The outer membrane radius was measured based on the SEM image visualization, while the cake radius was calculated using Eqn.-6.

$$
R_{c}(t)=\frac{1}{k_{c}} r_{0} \ln \frac{r_{c}(t)}{r_{0}}
$$

Where, $\mathrm{Rc}$ is cake resistant, $\mathrm{kc}$ is cake permeability $\left(\mathrm{m}^{-2}\right)$, and $\mathrm{t}$ is filtration time.

\section{Membrane Morphology}

\section{RESULTS AND DISCUSSION}

The morphological structure of the membrane was evaluated based on the SEM images of the whole crosssection, enlarged cross-section, outer surface, and wall of the macro void as shown in Fig.-1. The crosssection image shows that the membrane consists of an inner layer and an outer layer, with a finger-shaped macro void structure on each layer as well as the sponge structure in the middle. The asymmetric pore structure on the membrane with a non-unidirectional shape would provide resistance to the filtration process, which is called membrane resistance $(\mathrm{Rm}){ }^{11}$

The top surface of the SEM image (Fig.-1c) shows that the membrane surface structure is dense, with no clear pores visible although the image is zoomed up to 50,000 times. However, pore structures with the size of fewer than 200 microns can be found in the macro void walls (Fig.-1d).

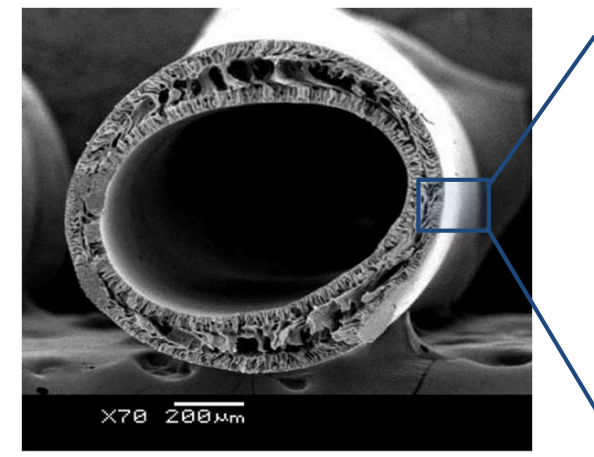

(a)

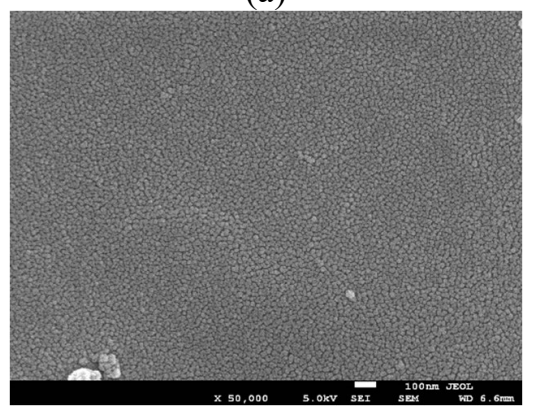

(c)

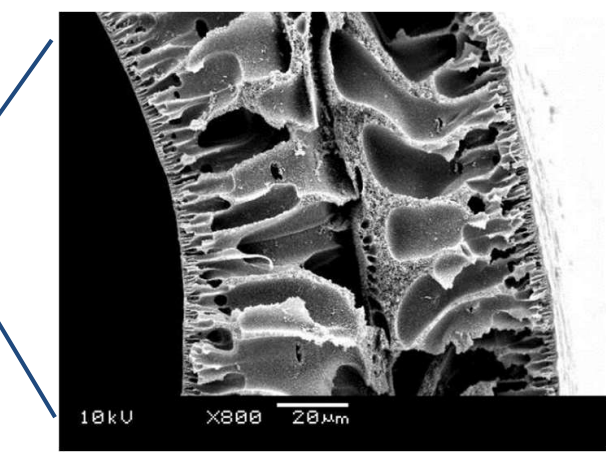

(b)

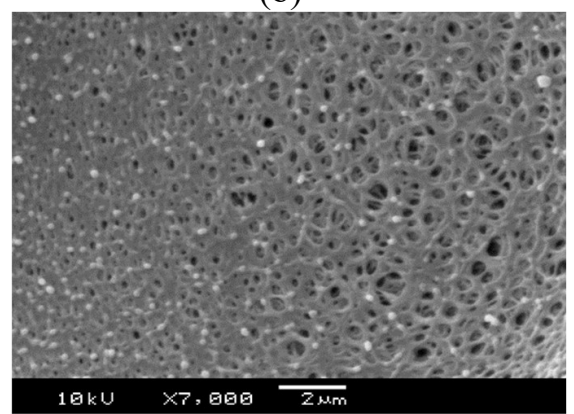

(d)

Fig.-1: Morphology of PES-OT Membrane based on SEM imaging: (a)Cross-section, (b)Enlarged Cross-section,

(c)Outer Surface, and (d)Wall of macro void.

\section{Permeability Profile of SA Vs Filtration Time and Volume of Permeate}

Acidity $(\mathrm{pH})$ is one of the chemical properties of the solution which also affects the phenomenon of fouling formation on the membrane. The profile of relative permeability of SA solution at neutral, acidic, and base $\mathrm{pH}$ conditions is shown in Fig.-2. It can be seen that a very significant decrease in the relative permeability of the solution took place in SA samples with acidic conditions. This phenomenon could take place because in highly acidic conditions $(\mathrm{pH}<3.5)$, SA tends to form a precipitate as the solution viscosity increases. ${ }^{12}$ Meanwhile, for the filtration of SA solution at the bases and neutral $\mathrm{pH}$ conditions, the results showed that the relative permeability value had a smaller decrease than that of the SA solution at acidic conditions. In addition, SA flux at base $\mathrm{pH}$ conditions tended to be more stable at a specific time and produced a larger 
RASĀYAN J. Chem.

Vol. 14 | No. 3 |1482-1488| July - September | 2021

amount of permeate. This phenomenon occurred because $\mathrm{pH}$ conditions affect the SA viscosity in general, where the higher the $\mathrm{pH}$ (between 5-10) the smaller the SA viscosity will be. The decrease in SA viscosity is due to the degradation of the $\beta$-eliminative by excess $\mathrm{OH}^{-}$ions. ${ }^{3}$ The decline in membrane performance for SA solution filtration under acidic conditions was also evident with less permeate volume than that in bases or neutral conditions (Fig.-2).

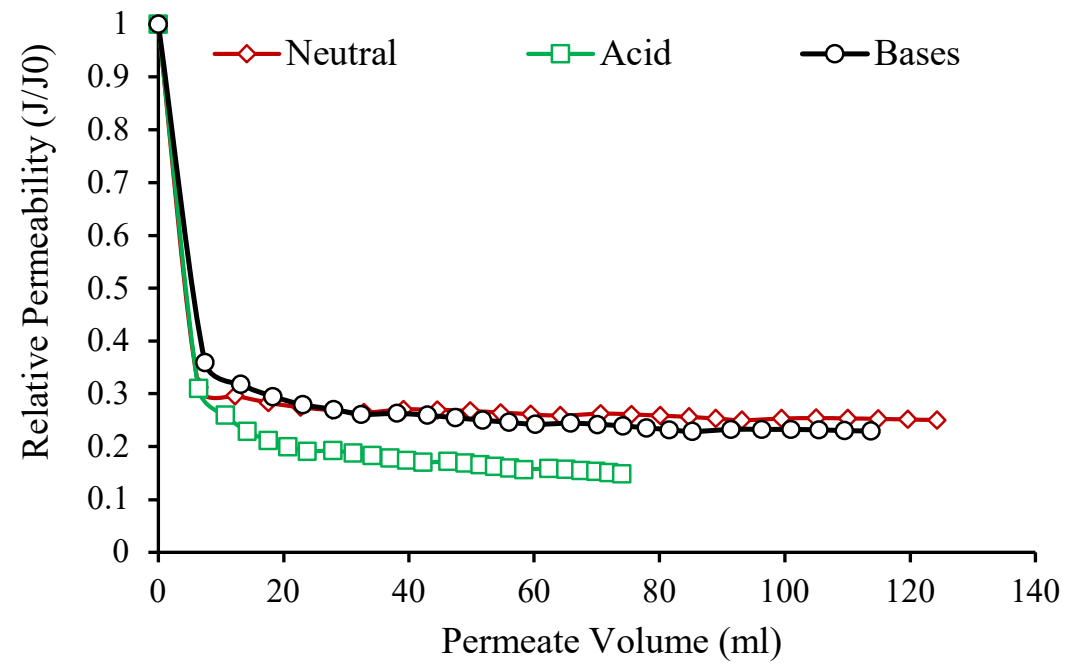

Fig.-2: The Relationship between the Relative Permeability and Permeate Volume, the Effect of Acidity for PES

\section{Performance Filtration with Backwash}

Aerosol OT Membrane

Membrane cleaning using backwash is usually done on membrane filtration at an industrial scale. The aim is to reduce the formation of fouling on the membrane surface and to extend the membrane lifetime. The backwash process in this study was carried out by applying cross-flow of deionized water across the membrane surface at $1 \mathrm{~atm}$ pressure for 5 minutes. The filtration profile of sodium alginate solution in neutral, basic, and acidic solutions is shown in Fig.-3, and the percentage of flux decline and flux recovery ratio is summarized in Table-2. The calculation of the FRR value aims to determine the effectiveness of the membrane performance after backwashing. The backwashing process on the membrane is expected to restore the membrane function by eliminating the formed fouling.

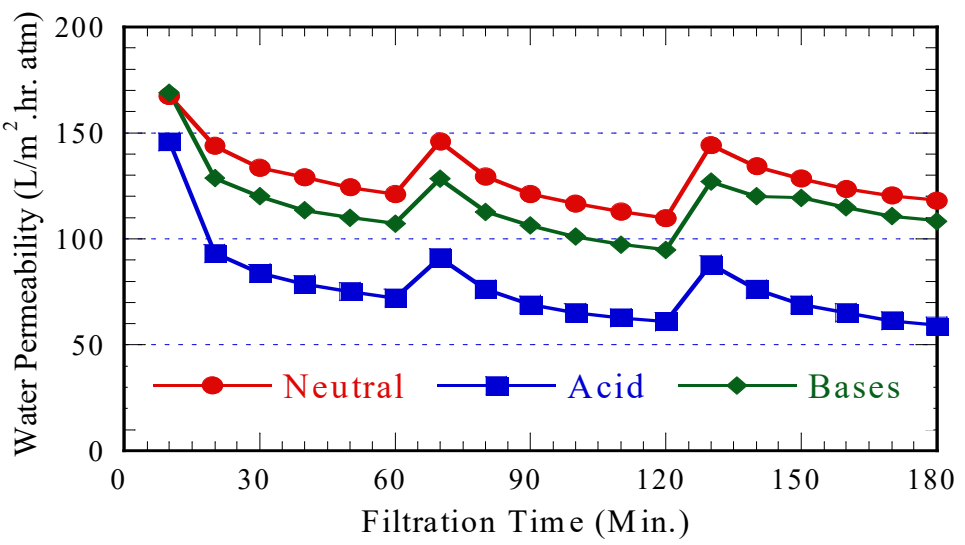

Fig. -3: Permeability of SA Solution with Backwash Treatment

From the filtration test and backwashing process of SA solution at various acidity, sodium alginate solution at neutral $\mathrm{pH}$ shows the best filtration profile. This is indicated by the lowest flux decline value at both backwash stages of 1 and 2. In addition, the filtration of sodium alginate solution at the acid conditions had significantly decreased the FRR value. This decrease could be due to the formation of thicker fouling on 
RASĀYAN J. Chem.

Vol. 14 | No. 3 |1482-1488| July - September | 2021

the membrane surface so that membrane cleaning (backwashing) by deionized water may not suffice and, therefore, additional materials capable of degrading the formed fouling would be necessary.

Table-2: Membrane Performance of SA Filtration at Neutral, Acidic, and Basic Conditions

\begin{tabular}{c|r|r|r|r|r|r}
\hline \multirow{2}{*}{$\begin{array}{c}\text { Backwashing } \\
\text { Stage }\end{array}$} & \multicolumn{3}{|c|}{ Permeability Decline (\%) } & \multicolumn{3}{c}{ Permeability Recovery Ratio (\%) } \\
\cline { 2 - 8 } & Neutral & \multicolumn{1}{|c|}{ Acid } & \multicolumn{1}{c}{ Bases } & Neutral & \multicolumn{1}{l}{ Acid } & \multicolumn{1}{c}{ Bases } \\
\hline I & 28 & 50 & 37 & 87.13 & 62.37 & 75.82 \\
\hline II & 34 & 58 & 43 & 86.15 & 60.31 & 75.51 \\
\hline
\end{tabular}

\section{The Increase of Cake Thickness on the Membrane Surface}

Fouling on the membrane can be formed by several mechanisms including the formation of cake on the surface, concentration polarization, and diffusion in the membrane pores. All these types of fouling will increase the cake layer formation on the membrane surface as the filtration time increases. In a hollow fiber membrane by a pressure-driven outside filtration flow system, the thickness of the cake layer is the difference between the cake radius $(\mathrm{rc})$ and the membrane outer radius $\left(\mathrm{r}_{0}\right)$.

From the entire period of filtration time, the alginate solution feed with acidic $\mathrm{pH}$ conditions formed the thickest cake. This means that the filtration process with the hollow fiber membrane by a pressure-driven outside flow system is not suitable for the highly acidic feed solutions (Fig.-4). This is because, at low pH $(<5)$, SA solutions tend to form deposits due to their relatively larger viscosity. From Fig.-4, it can also be inferred that the best filtration conditions with the lowest cake growth are with the solution filtration at a neutral $\mathrm{pH}$.

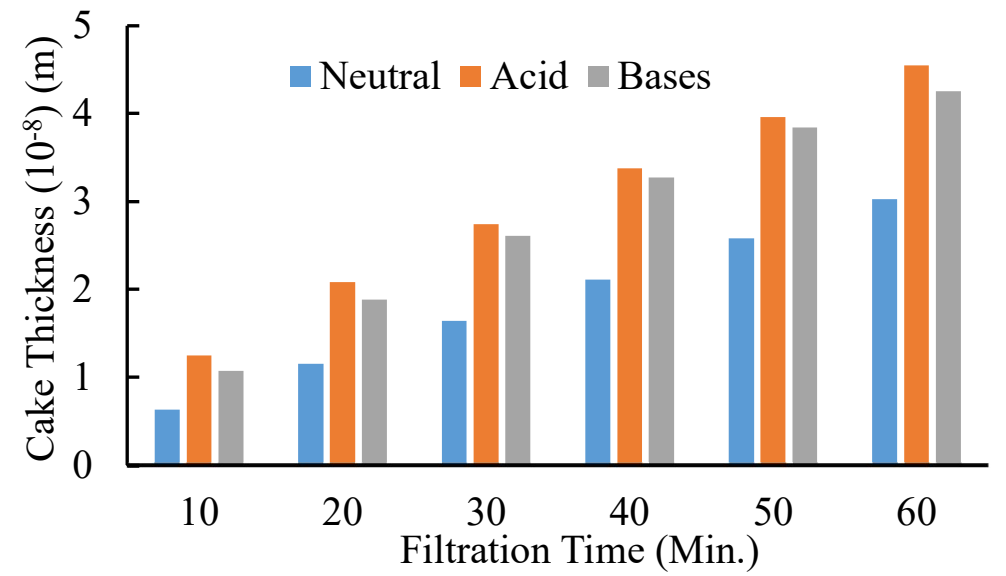

Fig.-4: The Increase in Cake Thickness Vs Filtration Time for PES Aerosol OT Membrane

\section{CONCLUSION}

PES/A-OT membranes have been used for the filtration of SA solutions at various acidity. The membrane relative permeability decreased significantly in the SA solution with acidic $\mathrm{pH}$, whereas at neutral $\mathrm{pH}$, it had the best relative permeability. The lowest flux recovery ratio (FRR) of the membrane was identified in the filtration test with acidic $\mathrm{pH}$, while the best FRR of $87.13 \%$ was obtained in the feed at neutral $\mathrm{pH}$. The thickest cake formation on the membrane surface was produced by filtration in an acidic condition reaching $4.55 \times 10^{-8} \mathrm{~m}$, while the thickness of cake formation at neutral $\mathrm{pH}$ was about $3.0 \times 10^{-8} \mathrm{~m}$.

\section{ACKNOWLEDGEMENT}

Acknowledgment for the Indonesian Ministry of Education and Culture as financial support of this research under research grant "Penelitian Dasar" 2020.

\section{REFERENCES}

1 M. Chen, C. T. Jafvert, Y. Wu, X. Cao and N. P. Hankins, Chemical Engineering Journal, 398, 125413(2020), https://doi.org/10.1016/j.cej.2020.125413

2 S. Al Aani, T. N. Mustafa and N. Hilal, Journal of Water Process Engineering, 35, 101241(2020), 
RASĀYAN J. Chem.

Vol. 14 | No. 3 |1482-1488| July - September | 2021

https://doi.org/10.1016/j.jwpe.2020.101241

3 X. Xu, L. Luo, C. Liu, Z. Zhang and D. J. McClements, Food Hydrocolloids, 63, 301(2017), https://doi.org/10.1016/j.foodhyd.2016.09.005

4 M. Y. Wahab, S. Muchtar, S. Mulyati, M. Riza, N. Arahman and M. A. A. Baig, Rasayan Journal of Chemistry, 12(3), 1135(2019), https://doi.org/10.31788/RJC.2019.1235340

5 Y. Ding, T. Li, K. Qiu, B. Ma and R. Wu, Environmental Research, 195, 110756(2021), https://doi.org/10.1016/j.envres.2021.110756

6 N. Arahman, S. Satria, F. Razi and M. R. Bilad, Water (Switzerland), 10(9), 1(2019), https://doi.org/10.3390/w10091207

7 N. H. Abd-Razak, A. Pihlajamäki, T. Virtanen, Y. M. John Chew and M. R. Bird, Food Bioproducts, Processing, 126, 184(2021), https://doi.org/10.1016/j.fbp.2021.01.009

8 K. Ohanessian, M. Monnot, P. Moulin, J. H. Ferrasse, C. Barca, A. Soric and O. Boutin, Chemical Engineering Research and Design, 158, 164(2020), https://doi.org/10.1016/j.cherd.2020.04.007

9 E. Iritani, N. Katagiri and H. Masuda, Chemical Engineering Research and Design, 134, 528(2018), https://doi.org/10.1016/j.cherd.2018.04.026

10 N. Arahman, T. Maruyama, T. Sotani and H. Matsuyama, Journal of Applied Polymer Science, 110, 687(2008), https://doi.org/10.1002/app.28719

11 S. Nazemidashtarjandi, S. A. Mousavi and D. Bastani, Journal of Water Process Engineering, 16, 170(2017), https://doi.org/10.1016/j.jwpe.2017.01.004

12 Q. Qomarudin, J. D. Orbell, L. Ramchandran, S. R. Gray, M. B. Stewart and T. Vasiljevic, Food Research International, 71, 23(2015), https://doi.org/10.1016/j.foodres.2015.02.024

[RJC-6260/2020] 